http://jmscr.igmpublication.org/home/

ISSN (e)-2347-176x ISSN (p) 2455-0450

crossref DOI: https://dx.doi.org/10.18535/jmscr/v9i7.30

Journal Of Medical Science And Clinical Research

IGM Publication

An Official Publication of IGM Publication

\title{
Assessment of Pain Perception after Surgical and Nonsurgical Periodontal Therapy- A Cross-Sectional Study
}

\author{
Authors \\ Dr Apoorva S.M', Dr Suma Prashanth ${ }^{2}$, Dr Suchetha. A ${ }^{3}$, Dr Sapna N ${ }^{4}$, \\ Dr Darshan. B. $\mathbf{M}^{5}$, Dr Divya Bhat ${ }^{6}$
}

1,4,5 Reader, Department of Periodontics, D.A. Pandu Memorial R.V. Dental College \& Hospital .ca-37, 24th Main, I phase J.P. Nagar, Bangalore

${ }^{2}$ MDS, D.A. Pandu Memorial R.V. Dental College \& Hospital .ca-37, 24th Main, I phase J.P. Nagar, Bangalore

${ }^{3}$ Professor \& HOD, Department of Periodontics, D.A. Pandu Memorial R.V. Dental College \& Hospital .ca37, 24th Main, I phase J.P. Nagar, Bangalore

${ }^{6}$ Senior Lecturer, Department of Periodontics, D.A. Pandu Memorial R.V. Dental College \& Hospital .ca-37, 24th Main, I phase J.P. Nagar, Bangalore

\section{Abstract}

Pain is an unpleasant sensory and emotional feeling accompanying existing or impending tissue damage. Periodontal disease is not necessarily painful. Conversely, periodontal treatment is experienced as painful by substantial numbers of patients. The intensity of pain differs with various nonsurgical and surgical periodontal therapies. This pain intensity perceived by patient has been recorded by the clinicians using visual analog scale. The visual analog scale isa measurement tool to assess the patient's pain perception.

Aim: To assess the perception of pain after surgical and nonsurgical periodontal therapies.

Methodology: 40 patients (between 20 and 65 years of age) with active periodontal sites and 20 periodontally healthy patients were selected and were divided into 3 groups: Group I $(n=20)$ - Healthy patients; Group II $(n=20)$ - those to be treated with surgical therapy (open flap debridement by raising Kirkland flap); Group III $(n=20)$ - those to be treated with nonsurgical therapy (Root planing). The degree of Pain was assessed using visual analog scale after 2 hours of periodontal therapy in group II and group III and immediately after scaling in group I patients. All the 3 groups were matched according to the age and gender. Collected data were tabulated and analyzed statistically using Independent Student $t$ test and Chi square test.

Results: In group I, 65\% (N=13) of the respondents had no pain, 35\% (N=7) had mild pain and none had moderate and severe pain. In group II, 5\% $(N=1)$ of the respondents had no pain, $60 \%(N=12)$ had mild pain, 35\% (N=7) had moderate pain, and none had severe pain. In group III, 50\% (N=10) of the respondents had no pain, $50 \%(N=10)$ had mild pain and none had moderate pain and severe pain. And the difference in the pain perception levels among all the 3 groups were statistically significant $\left(\chi^{2}=\right.$ 25.06).

Conclusion: The pain perception level showed statistically significant difference between healthy and surgical group, surgical and nonsurgical group, but the difference was not statistically significant between the healthy and nonsurgical group. The results of this study were found to be beneficial as it provided a feed back to clinician. It helps in further modification to be taken in to consideration during the procedure thereby reducing patient's anxiety and pain perception after the procedure. 


\section{Introduction}

Pain is an unpleasant sensory and emotional feeling accompanying existing or impending tissue damage or referenced to such damage. Pain is the most common experience reported by patients, and patient anxiety is a form of warning signal. It is a sensual and perceptual phenomenon, which causes suffering. Pain has many forms, it warns against damage to the body, which is important for avoiding injuries and consequently for survival. Pain is unpleasant for the patient and it can alter person's life, reduce the quality of life, and have an impact on the patient's family. The word "pain" for the patient means disease and suffering, for the doctor it is a symptom, and for the physiologist it is a kind of feeling that has its own anatomical and physiological system which begins with the receptors and ends up in the brain cortex. Feeling is a physical sensation that can be confirmed by electrophysiological methods, but in practice it is only a subjective sensation. Its intensity and quality come under various internal and external factors; therefore, the same stimulus can be experienced differently in different circumstances, somatic and psychiatric conditions. $^{1}$

Pain is also more likely to be reported by those with previous painful experiences and those who are anxious about dental treatment including any periodontal therapies. Perception of pain and dental anxiety differ with various periodontal therapies. Scaling and root planing (SRP) are the most commonly used procedure for treating gingivitis and periodontitis, which is considered as painful procedure. $^{2}$

Patient discomfort during periodontal treatments, postoperative pain and postoperative dentin hypersensitivity are common clinical events. Periodontal disease is not necessarily painful. Conversely, periodontal treatment is experienced as painful by substantial numbers of patients. SRP can be quite painful for patients with chronic periodontitis. The intensity of pain or discomfort has been perceived by clinicians to differ dramatically between patients. ${ }^{3}$
The visual analog scale (VAS) is a measurement tool to evaluate dental pain. The VAS is a simple, reliable and valid method to assess pain intensity. Matthews and McCullocht used visual analog scales to investigate differences between patients in their assessment of surgical and non-surgical periodontal treatment. ${ }^{4}$

There are studies in the literature which assess the pain perception after surgical procedures like modified widman flap, gingivectomy, open flap with osseous resection ${ }^{5}$ and implant surgeries. ${ }^{6}$ There are studies which assess the pain perception after nonsurgical procedures like scaling ${ }^{2}$ and root planing. ${ }^{5}$ Since no previous study had been carried out comparing pain perception after surgical (open flap debridement raising kirkland flap) and nonsurgical procedure (root planing),this study was conducted to assess the perception of pain after surgical and nonsurgical periodontal therapies.

\section{Materials and Methods}

A questionnaire study was conducted among the selected subjects who were included in the following three groups according to the treatment they received (healthy group, surgical group and nonsurgical group).The ethical clearance for the study was obtained from the ethical committee and review board of the institution. The nature of the study was explained verbally in a language comprehensible to the patient, information sheet was given, and informed consent was obtained from the patient.

40 patients (between 20 and 65 years of age) with active periodontal sites and 20 periodontally healthy patients were selected. The subjects were included in the study based on the following inclusion and exclusion criteria

Inclusion Criteria- Patients diagnosed with chronic periodontitis (AAP, 1999) aged about 20 and 65 years were included in the study. Healthy patients who required oral prophylaxis (group I), patients who required surgical therapy (group II), but who have not undergone periodontal surgical therapy before and patients requiring nonsurgical 
therapy (group III) who have not undergone any sort of periodontal treatment before were included in the study.

Exclusion criteria's- Pregnant and lactating patients, smokers, patients who had taken analgesics or sedatives or antidepressants within 24 hours of treatment and mentally challenged patients.

The subjects were randomly selected from those undergoing surgical and nonsurgical therapy for the first time and periodontally healthy patients requiring oral prophylaxis. 60 patients were identified and divided into 3 groups. Group $\mathrm{I}(\mathrm{n}=20)$ - Healthy patients requiring oral prophylaxis. Group II $(n=20)$-Those to be treated with surgical therapy (open flap debridement by raising Kirkland flap).Group III $(n=20)$-Those to be treated with nonsurgical therapy (Root planing). All the 3 groups were matched according to the age and gender.

The degree of Pain was assessed using visual analog scale. VAS is a straight horizontal line of fixed length, usually $100 \mathrm{~mm}$. The ends are defined as the extreme limits of the parameter to be measured orientated from the left (worst) to the right (best). Using a ruler, the score is determined by measuring the distance $(\mathrm{mm})$ on the $10-\mathrm{cm}$ line between the "no pain" and the patient's mark, providing a range of scores from $0-100$. The patient was asked to indicate a point along the line at the position which they feel represents their perception of their current state. A higher score indicates greater pain intensity. The following cut points on the pain VAS have been recommended: no pain (0-4 mm), mild pain (5-44 mm), moderate pain $(45-74 \mathrm{~mm})$, and severe pain $(75-100 \mathrm{~mm}){ }^{7}$ (Annexure I)

All the patients included in the study were asked to mark the pain score they experienced during the periodontal therapy on VAS. Pain score were marked after 2 hours by the time local anesthetic effect wears off and before patient received the first dose of analgesics. Pain scores of the healthy individuals were marked on the VAS immediately after scaling as local anesthesia was not administered. The patients were asked to wait in the Department of Periodontics to mark the pain score. Collected data was tabulated and analyzed statistically. Differences in age group, gender, treatment duration and pain perception levels among respondents of all the 3 study groups were tested using chi square test $(\chi 2)$. Mean pain perception scores between the study groups were tested using independent ' $t$ ' test.

\section{Results}

Age Distribution: The study respondents were classified based on age groups namely 20- 31 years, 32- 45 years and 46- 55 years.

In Group I, 9 subjects were included in 20- 31 years age group, 5 subjects under 32- 45 years age group and 6 subjects under 46- 55 years age group. In Group II, 9 subjects were included in 20- 31 years age group, 5subjects under 32- 45 years age group and 6 subjects under 46- 55 years age group. In Group III, 6subjects were included in 20- 31 years age group, 9 subjects under 32- 45 years age group and 5 subjects under $46-55$ years age group. There was no statistical difference in age distribution among the 3 groups $(\chi 2=2.52)$. (Table 1)

\section{Gender Distribution}

Here respondents were grouped based on the gender among all the 3 groups. In group I and II, 11 male respondents and 9 female respondents were included. And in group III, both male and female respondents were 10 in number. There was no statistical difference in gender distribution among the 3 groups $(\chi 2=.13)$. (Table 2$)$

\section{Duration of Treatment}

Study respondents were classified based on duration of treatment received such as 15- 25 minutes, 26- 60 minutes and above 60 minutes. In group I, scaling was performed for all the respondents where 16 respondents were grouped in 15- 25 minutes, 4 respondents were grouped in 26- 60 minutes. In group II, OFD was performed for all the respondents where 18 respondents were grouped in above 60 minutes, 2 respondents were grouped in 26- 60 minutes. In group III, scaling 
and root planing was performed for all the respondents where 8 respondents were grouped in 15- 25 minutes, 12 respondents were grouped in 26- 60 minutes. There was statistically significant difference in terms of duration of treatment among the 3 groups $(\chi 2=61.33)$. (Table 3 ) The shorter the duration taken for the periodontal therapy lesser was the intensity of pain.

Pain perception levels in all the respondents among the 3 groups.

In group I, 13 respondents had no pain and 7 respondents had mild pain. In group II, one of the respondents had no pain, 12 respondents had mild pain and 7 respondents had moderate pain. In group III, 10 of the respondents had no pain, 10 respondents had mild pain. There was difference in the level of pain perception associated with different periodontal therapy which was statistically significant $(\chi 2=25.06)$. (Table 4$)$.

\section{Pain perception levels compared between group I and group II}

In group I, 13 of the respondents had no pain, 7 respondents had mild pain. In group II, one of the respondents had no pain, 12 respondents had mild pain and 7 respondents had moderate pain. Differences in pain perception levels between group I (healthy respondents) and group II (surgical therapy respondents) was statistically significant $(\chi 2=18.60)$. (Table $5 \&$ Graph 4)

Mean pain perception scores in group I (healthy respondents) and group II (surgical therapy respondents) are $4.1 \quad \pm 3.8$ and $37.3 \pm 19.8$ respectively. Hence the difference in mean scores were statistically significant $(\mathrm{t}=7.36)$. (Table 8$)$

Pain perception levels compared between group I and group III

In group I, 13 respondents had no pain and 7respondents had mild pain. In group III, 10 of the respondents had no pain and 10 respondents had mild pain. The difference in pain perception levels between group I and group III were statistically not significant $(\chi 2=0.92)$. (Table 6\& Graph 5)

Mean pain perception scores in group I (healthy respondents) and group III (nonsurgical therapy respondents) were $4.1 \pm 3.8$ and $12.3 \pm 15.6$ respectively. Hence the difference in mean scores was statistically significant $(\mathrm{t}=2.28)$. (Table 9$)$

Pain perception levels compared between group II and group III

In group II, one of the respondents had no pain, 12 respondents had mild pain and 7 respondents had moderate pain. In group III, 10 respondents had no pain and 10 respondents had mild pain. And the difference in pain perception levels between group II and group III were statistically significant $(\chi 2=14.55)$. (Table $7 \&$ Graph 6)

Mean pain perception scores in group II (surgical therapy respondents) and group III (nonsurgical therapy respondents) were $37.3 \pm 19.8$ and $12.3 \pm 15.6$ respectively. Hence the difference in mean scores was statistically significant $(\mathrm{t}=4.44)$. (Table 10)

Table - 1: Classification of Respondents by Age group

\begin{tabular}{|c|c|c|c|c|c|c|}
\hline \multirow{2}{*}{ Age group (years) } & \multicolumn{7}{|c|}{ Respondents } \\
\cline { 2 - 7 } & \multicolumn{2}{|c|}{ Healthy } & \multicolumn{2}{c|}{ Surgical therapy } & \multicolumn{2}{c|}{ Nonsurgical therapy } \\
\cline { 2 - 7 } & $\mathrm{N}$ & $\%$ & $\mathrm{~N}$ & $\%$ & $\mathrm{~N}$ & $\%$ \\
\hline $20-31$ & 9 & 45.0 & 9 & 45.0 & 6 & 30.0 \\
\hline $32-45$ & 5 & 25.0 & 5 & 25.0 & 9 & 45.0 \\
\hline $46-55$ & 6 & 30.0 & 6 & 30.0 & 5 & 25.0 \\
\hline Total & $\mathbf{2 0}$ & $\mathbf{1 0 0 . 0}$ & $\mathbf{2 0}$ & $\mathbf{1 0 0 . 0}$ & $\mathbf{2 0}$ & $\mathbf{1 0 0 . 0}$ \\
\hline $\boldsymbol{7}$ & \multicolumn{7}{|c|}{$\chi^{2}(0.05,4 \mathrm{df})=9.488$} \\
\hline
\end{tabular}

Table - 2: Classification of Respondents by Gender

\begin{tabular}{|c|c|c|c|c|c|c|}
\hline \multirow[t]{3}{*}{ Gender } & \multicolumn{6}{|c|}{ Respondents } \\
\hline & \multicolumn{2}{|c|}{ Healthy } & \multicolumn{2}{|c|}{ Surgical therapy } & \multicolumn{2}{|c|}{ Nonsurgical therapy } \\
\hline & $\mathrm{N}$ & $\%$ & $\mathrm{~N}$ & $\%$ & $\mathrm{~N}$ & $\%$ \\
\hline Male & 11 & 55.0 & 11 & 55.0 & 10 & 50.0 \\
\hline Female & 9 & 45.0 & 9 & 45.0 & 10 & 50.0 \\
\hline Total & 20 & 100.0 & 20 & 100.0 & 20 & 100.0 \\
\hline$\chi 2-$ Test & \multicolumn{6}{|c|}{$0.13^{\mathrm{NS}}$} \\
\hline
\end{tabular}


Table - 3: Classification of Respondents by Treatment done

\begin{tabular}{|c|c|c|c|c|c|c|}
\hline \multirow[t]{3}{*}{ Treatment done } & \multicolumn{6}{|c|}{ Respondents } \\
\hline & \multicolumn{2}{|c|}{ Healthy } & \multicolumn{2}{|c|}{ Surgical therapy } & \multicolumn{2}{|c|}{ Nonsurgical therapy } \\
\hline & $\mathrm{N}$ & $\%$ & $\mathrm{~N}$ & $\%$ & $\mathrm{~N}$ & $\%$ \\
\hline $15-25 \mathrm{~min}$ & 16 & 80.0 & 0 & 0.0 & 8 & 40.0 \\
\hline $26-60 \mathrm{~min}$ & 4 & 20.0 & 2 & 10.0 & 12 & 60.0 \\
\hline Above $60 \mathrm{~min}$ & 0 & 0.0 & 18 & 90.0 & 0 & 0.0 \\
\hline Total & 20 & 100.0 & 20 & 100.0 & 20 & 100.0 \\
\hline$\chi^{2}-$ Test & \multicolumn{6}{|c|}{ 61.33* } \\
\hline
\end{tabular}

*Significant at $5 \%$ level,

$\chi 2(0.05,4 \mathrm{df})=9.488$

Table - 4: Classification of Respondents by Pain perception level

\begin{tabular}{|c|c|c|c|c|c|c|c|}
\hline \multirow{3}{*}{$\begin{array}{c}\text { Pain perception } \\
\text { level }\end{array}$} & \multirow[t]{3}{*}{ Scores } & \multicolumn{6}{|c|}{ Respondents } \\
\hline & & \multicolumn{2}{|c|}{ Healthy } & \multicolumn{2}{|c|}{ Surgical therapy } & \multicolumn{2}{|c|}{ Nonsurgical therapy } \\
\hline & & $\mathrm{N}$ & $\%$ & $\mathrm{~N}$ & $\%$ & $\mathrm{~N}$ & $\%$ \\
\hline No pain & $0-4$ & 13 & 65.0 & 1 & 5.0 & 10 & 50.0 \\
\hline Mild pain & $5-44$ & 7 & 35.0 & 12 & 60.0 & 10 & 50.0 \\
\hline Moderate pain & $45-74$ & 0 & 0.0 & 7 & 35.0 & 0 & 0.0 \\
\hline Severe pain & $75-100$ & 0 & 0.0 & 0 & 0.0 & 0 & 0.0 \\
\hline \multicolumn{2}{|l|}{ Total } & 20 & 100.0 & 20 & 100.0 & 20 & 100.0 \\
\hline \multicolumn{2}{|c|}{$\chi 2-$ Test } & \multicolumn{6}{|c|}{$25.06 *$} \\
\hline
\end{tabular}

${ }^{*}$ Significant at $5 \%$ level, $\chi 2(0.05,4 \mathrm{df})=9.488$

Table - 5: Response on Pain perception level among Healthy and Surgical therapy Respondents

\begin{tabular}{|c|c|c|c|c|c|c|}
\hline \multirow{3}{*}{$\begin{array}{c}\text { Pain perception } \\
\text { level }\end{array}$} & \multirow[t]{3}{*}{ Scores } & \multicolumn{4}{|c|}{ Respondents } & \multirow{3}{*}{$\begin{array}{c}\chi^{2} \\
\text { Test }\end{array}$} \\
\hline & & \multicolumn{2}{|c|}{ Healthy } & \multicolumn{2}{|c|}{ Surgical therapy } & \\
\hline & & $\mathrm{N}$ & $\%$ & $\mathrm{~N}$ & $\%$ & \\
\hline No pain & $0-4$ & 13 & 65.0 & 1 & 5.0 & \multirow{4}{*}{$18.60 *$} \\
\hline Mild pain & $5-44$ & 7 & 35.0 & 12 & 60.0 & \\
\hline Moderate pain & $45-74$ & 0 & 0.0 & 7 & 35.0 & \\
\hline Severe pain & $75-100$ & 0 & 0.0 & 0 & 0.0 & \\
\hline Total & & 20 & 100.0 & 20 & 100.0 & \\
\hline
\end{tabular}

*Significant at 5\% level, $\quad \chi 2(0.05,2 \mathrm{df})=5.991$

Table - 6: Response on Pain perception level among Healthy and Nonsurgical therapy Respondents

\begin{tabular}{|c|c|c|c|c|c|c|}
\hline \multirow{3}{*}{$\begin{array}{c}\text { Pain perception } \\
\text { level }\end{array}$} & \multirow[t]{3}{*}{ Scores } & \multicolumn{4}{|c|}{ Respondents } & \multirow{3}{*}{$\begin{array}{c}\chi^{2} \\
\text { Test }\end{array}$} \\
\hline & & \multicolumn{2}{|c|}{ Healthy } & \multicolumn{2}{|c|}{ Nonsurgical therapy } & \\
\hline & & $\mathrm{N}$ & $\%$ & $\mathrm{~N}$ & $\%$ & \\
\hline No pain & $0-4$ & 13 & 65.0 & 10 & 50.0 & \multirow{4}{*}{$0.92^{\mathrm{NS}}$} \\
\hline Mild pain & $5-44$ & 7 & 35.0 & 10 & 50.0 & \\
\hline Moderate pain & $45-74$ & 0 & 0.0 & 0 & 0.0 & \\
\hline Severe pain & $75-100$ & 0 & 0.0 & 0 & 0.0 & \\
\hline Total & & 20 & 100.0 & 20 & 100.0 & \\
\hline
\end{tabular}

NS: Non-significant $\quad \chi^{2}(0.05,1 \mathrm{df})=3.841$

Table - 7: Response on Pain perception level among Surgical and non-surgical therapy and Nonsurgical therapy Respondents

\begin{tabular}{|c|c|c|c|c|c|c|}
\hline \multirow{3}{*}{$\begin{array}{c}\text { Pain perception } \\
\text { level }\end{array}$} & \multirow[t]{3}{*}{ Scores } & \multicolumn{4}{|c|}{ Respondents } & \multirow{3}{*}{$\begin{array}{c}\chi^{2} \\
\text { Test }\end{array}$} \\
\hline & & \multicolumn{2}{|c|}{ Surgical therapy } & \multicolumn{2}{|c|}{ Nonsurgical therapy } & \\
\hline & & $\mathrm{N}$ & $\%$ & $\mathrm{~N}$ & $\%$ & \\
\hline No pain & $0-4$ & 1 & 5.0 & 10 & 50.0 & \multirow{4}{*}{$14.55 *$} \\
\hline Mild pain & $5-44$ & 12 & 60.0 & 10 & 50.0 & \\
\hline Moderate pain & $45-74$ & 7 & 35.0 & 0 & 0.0 & \\
\hline Severe pain & $75-100$ & 0 & 0.0 & 0 & 0.0 & \\
\hline Total & & 20 & 100.0 & 20 & 100.0 & \\
\hline
\end{tabular}

*Significant at 5\% level, $\quad \chi^{2}(0.05,2 \mathrm{df})=5.991$ 


\section{JMSCR Vol||09||Issue ||07||Page 173-183||July}

Table - 8: Response on Pain perception scores among Healthy and Surgical therapy Respondents

\begin{tabular}{|c|c|c|c|c|}
\hline Group & Respondents & \multicolumn{2}{|c|}{ Pain scores } & 't' \\
\cline { 3 - 4 } & & Mean & SD & Test \\
\hline I & Healthy & 4.1 & 3.8 & $\mathbf{7 . 3 6}^{*}$ \\
\hline II & Surgical therapy & 37.3 & 19.8 & \\
\hline
\end{tabular}

Table - 9: Response on Pain perception scores among Healthy and Nonsurgical therapy Respondents

\begin{tabular}{|c|c|c|c|c|}
\hline Group & Respondents & \multicolumn{2}{|c|}{ Pain scores } & 't' \\
\cline { 3 - 4 } & & Mean & SD & Test \\
\hline I & Healthy & 4.1 & 3.8 & $\mathbf{2 . 2 8}^{*}$ \\
\hline III & Nonsurgical therapy & 12.3 & 15.6 & \\
\hline
\end{tabular}

Table - 10: Response on Pain perception scores among Surgical therapy and Nonsurgical therapy Respondents

\begin{tabular}{|c|c|c|c|c|}
\hline Group & Respondents & \multicolumn{2}{|c|}{ Pain scores } & 't' \\
\cline { 3 - 4 } & & Mean & SD & Test \\
\hline II & Surgical therapy & 37.3 & 19.8 & $\mathbf{4 . 4 4}^{*}$ \\
\hline III & Nonsurgical therapy & 12.3 & 15.6 & \\
\hline
\end{tabular}

Graph 1: Classification of Respondents by Age group

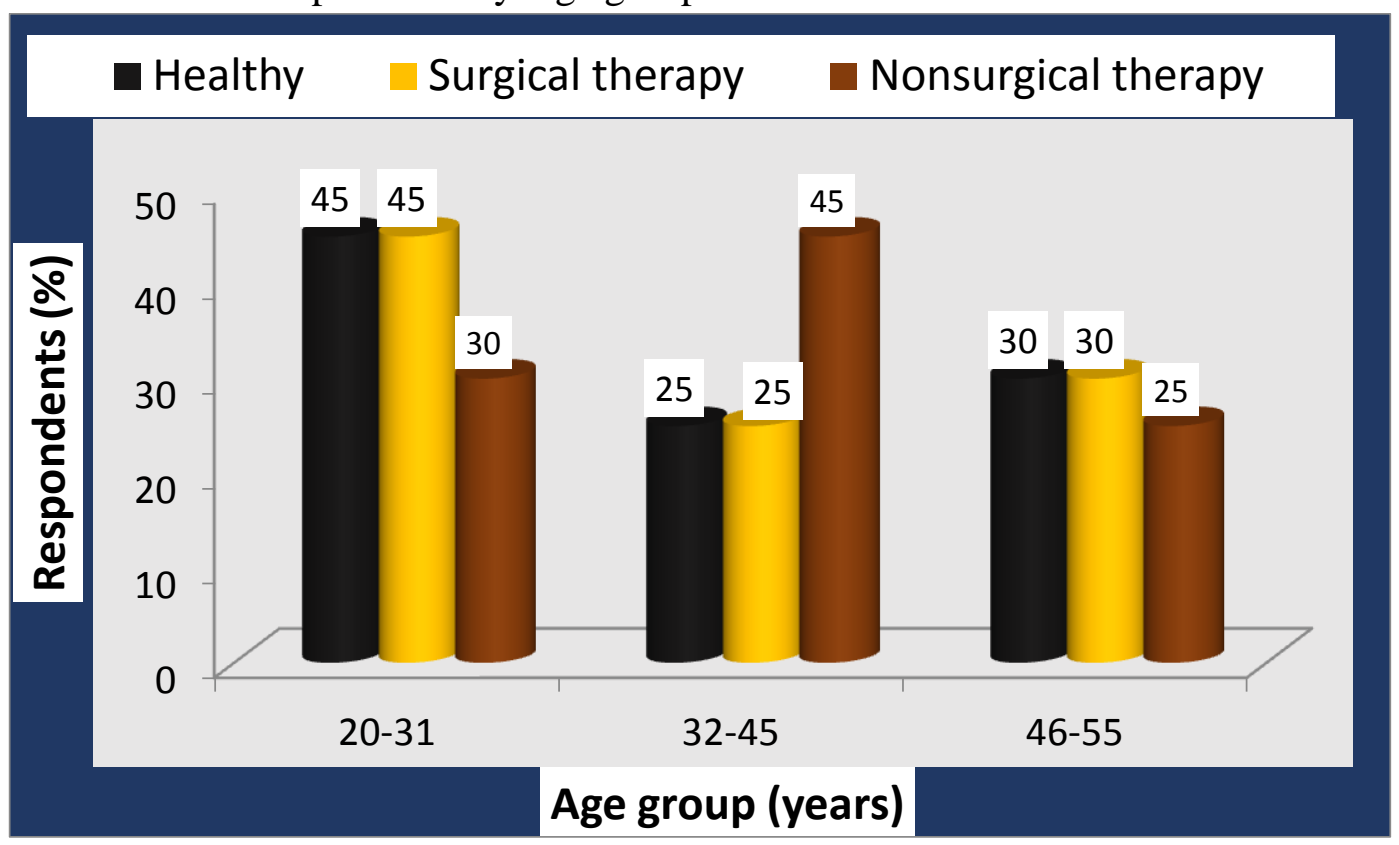




\section{JMSCR Vol||09||Issue||07||Page 173-183||July}

Graph 2: Classification of Respondents by Gender

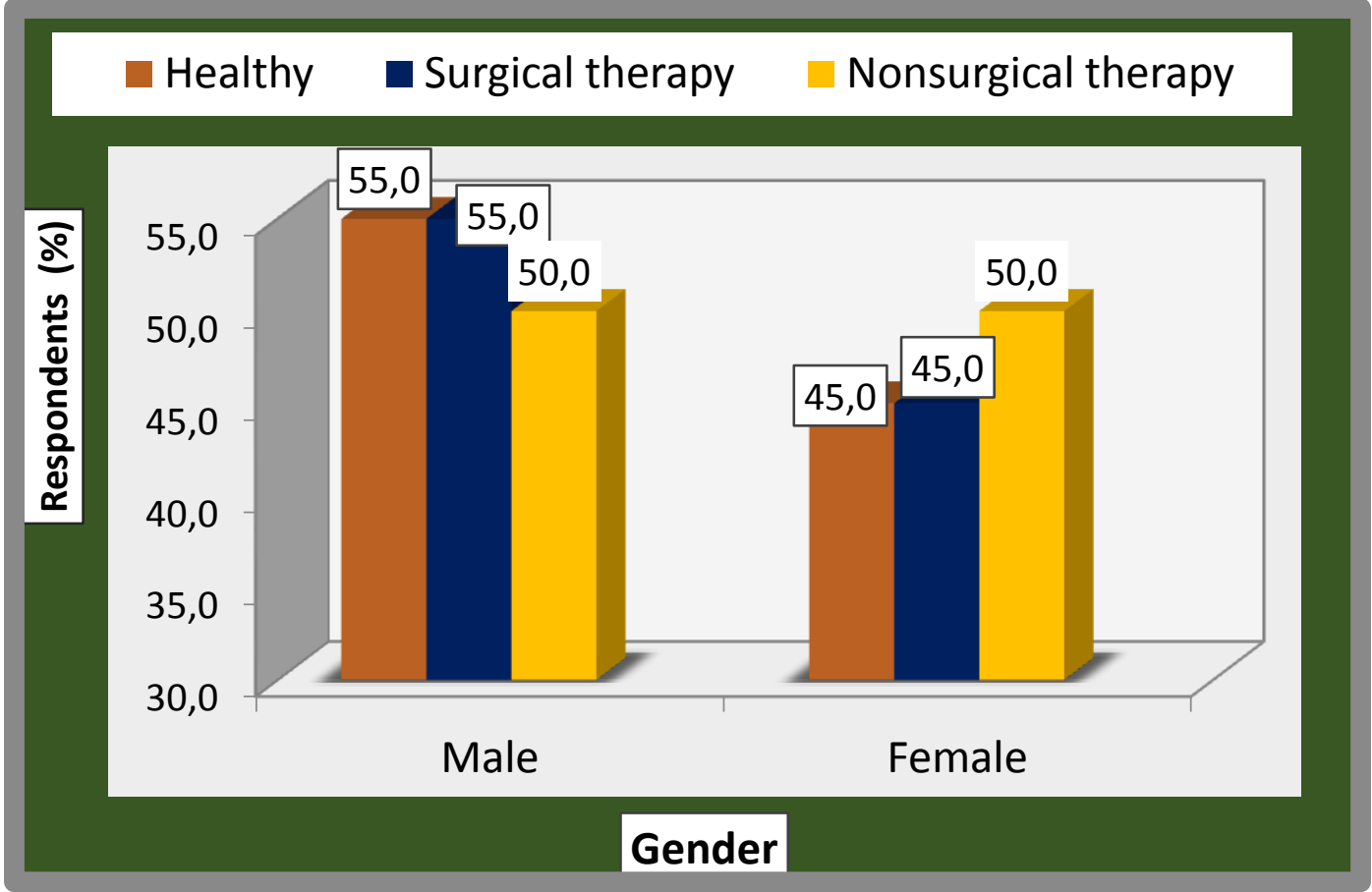

Graph 3: Classification of Respondents by Treatment done

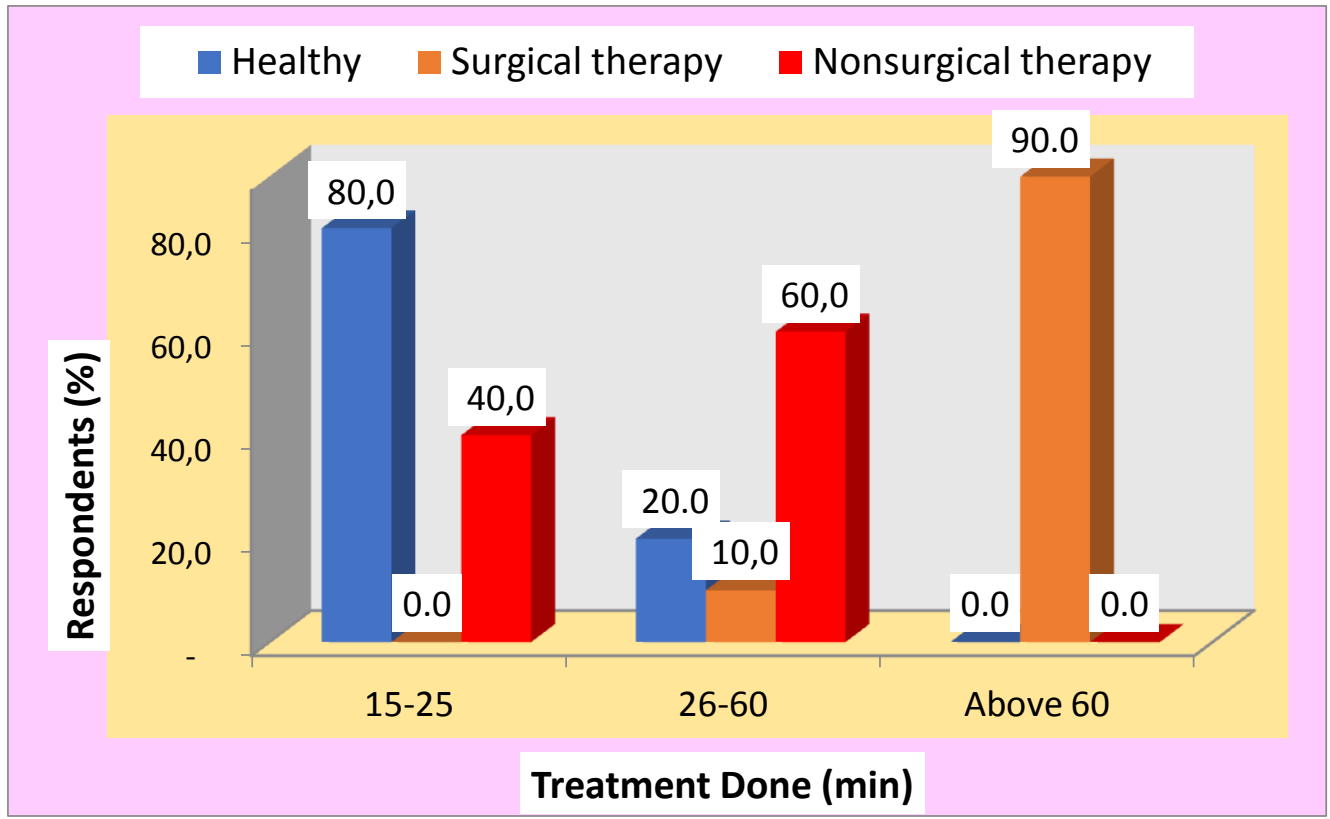




\section{JMSCR Vol||09||Issue ||07||Page 173-183||July}

Graph 4: Response on Pain perception level among Healthy and Surgical therapy Respondents

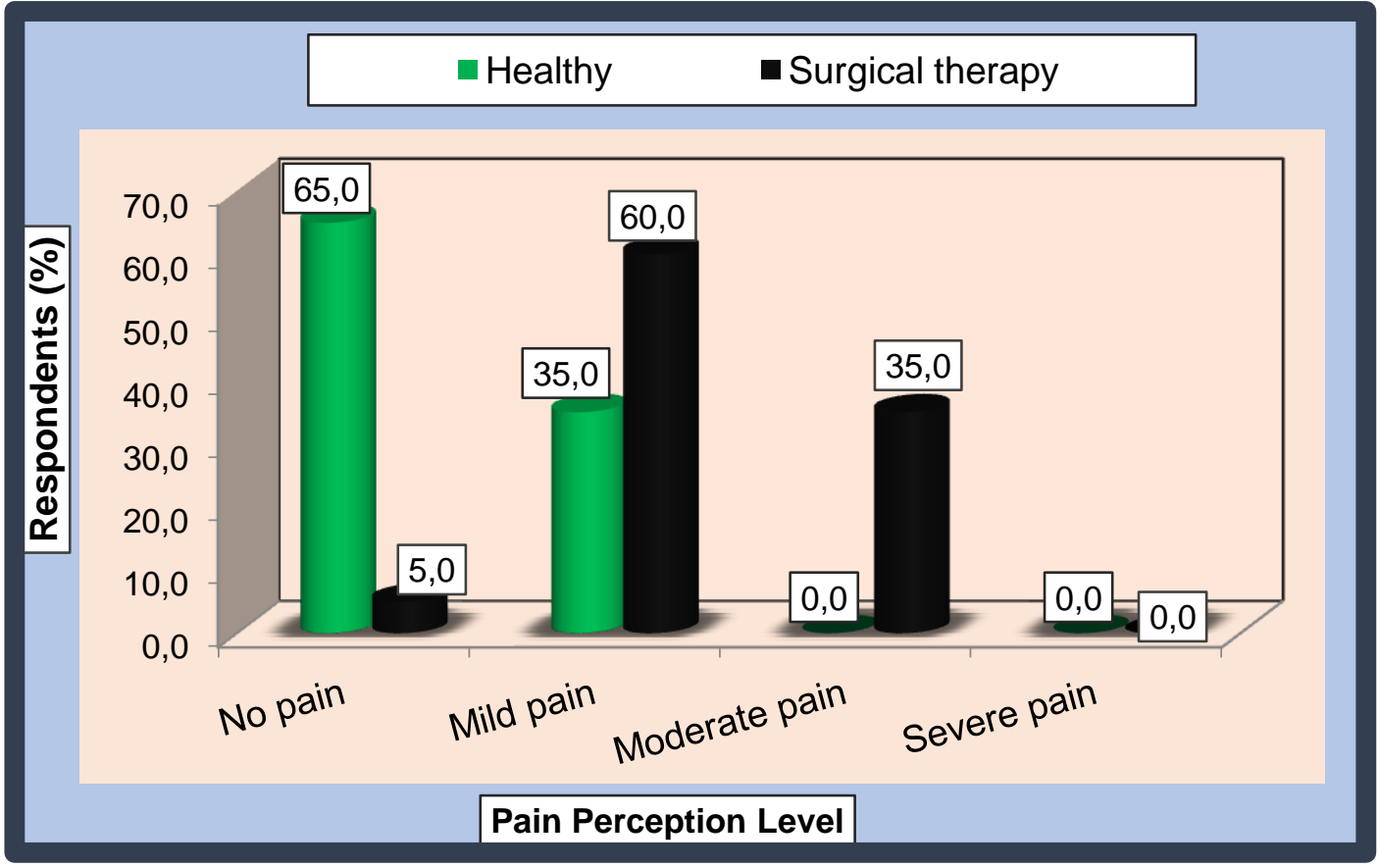

Graph 5: Response on Pain perception level among Healthy and Nonsurgical therapy Respondents

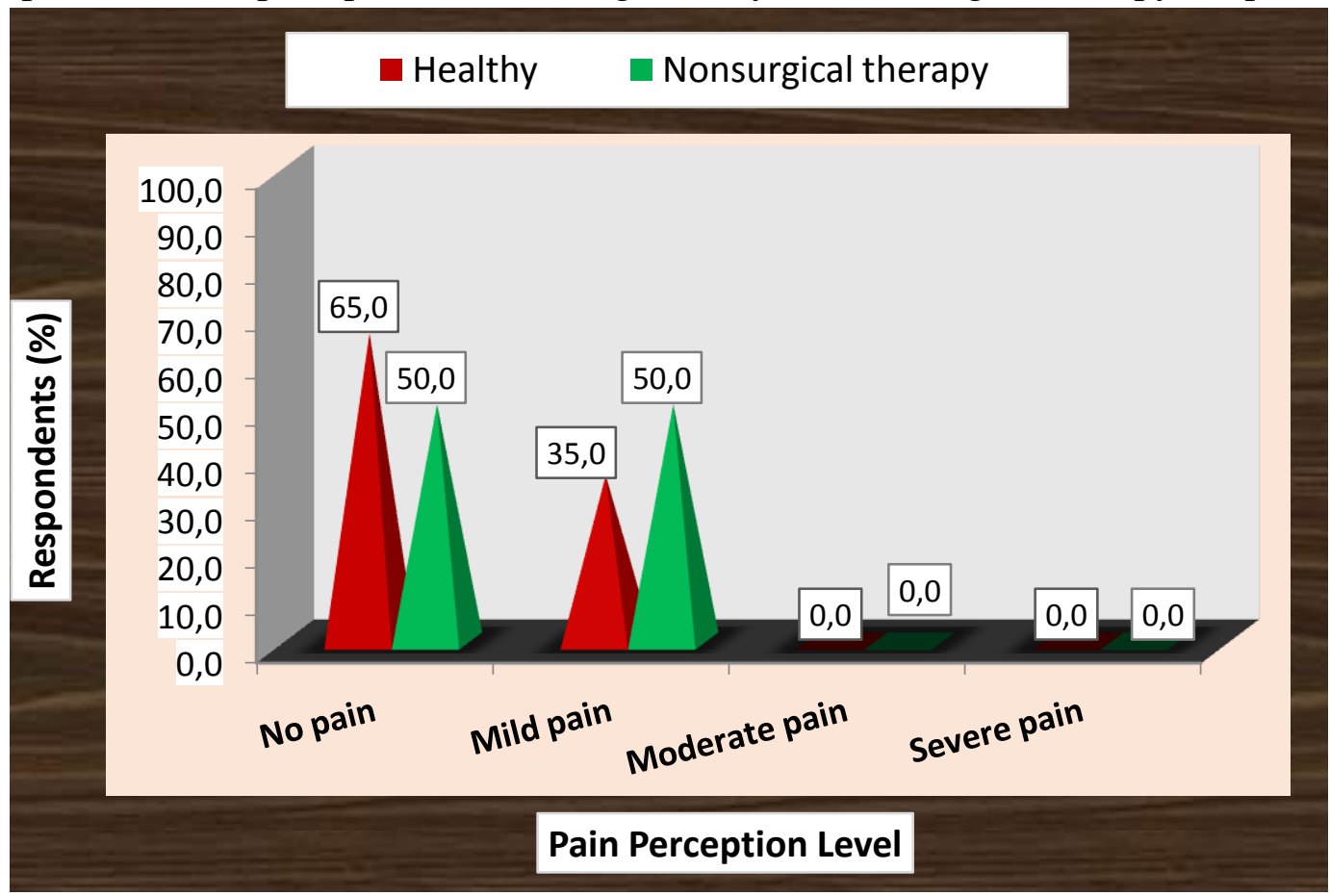


Graph 6: Response on Pain perception level among Surgical therapy and Nonsurgical therapy Respondents

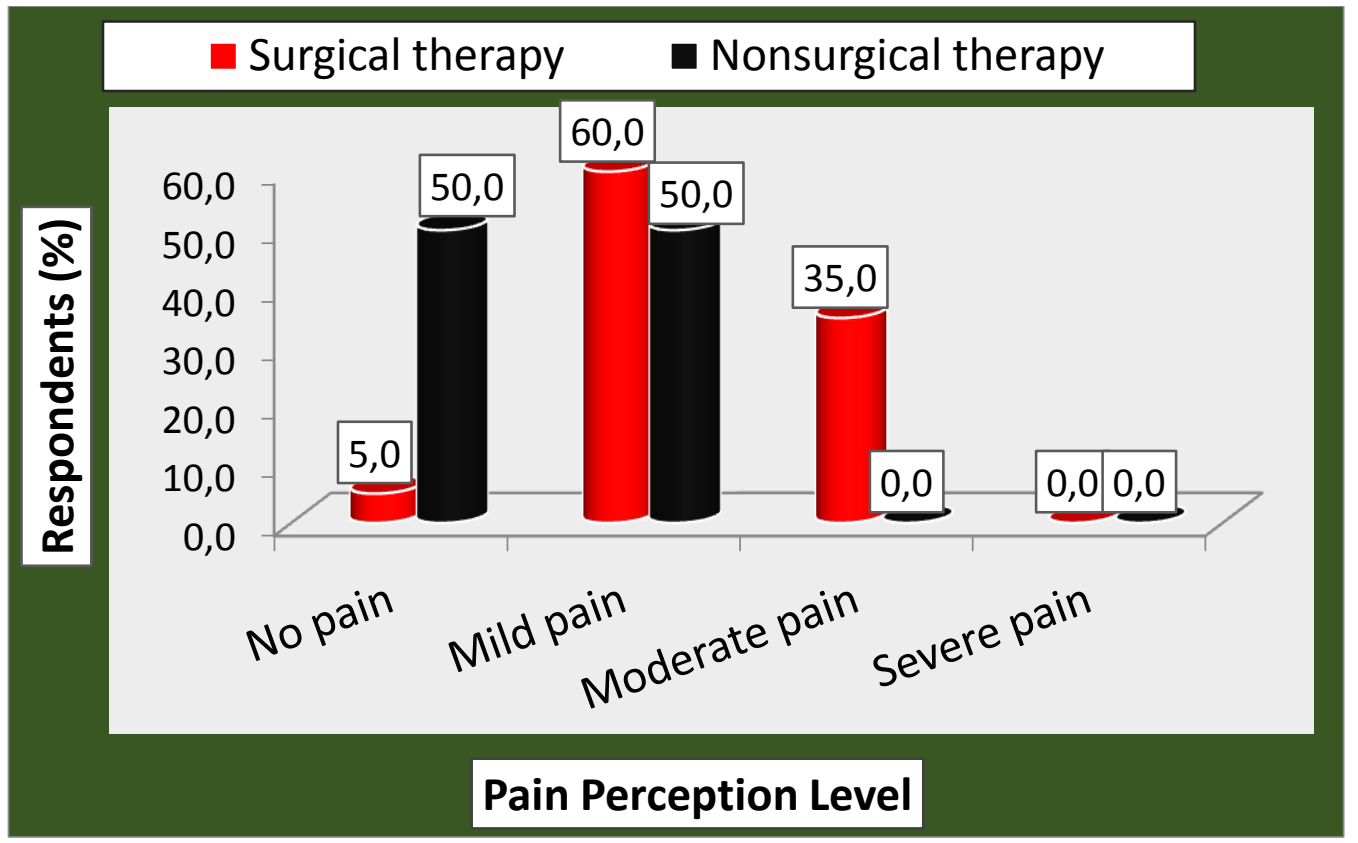

\section{Discussion}

In the field of periodontology, the instruments for evaluating clinical outcomes, such as probing depth (PD), clinical attachment loss and bleeding on probing are widely accepted and used. However, in periodontal disease, inflammation and destruction of the periodontium produces a wide range of signs and symptoms that may have an impact on the quality of life. ${ }^{8}$ These clinical indicators fail to identify the symptoms that are perceived by the subject, such as pain or satisfaction with treatment, and do not report the individual's welfare. ${ }^{9}$ A greater understanding about the consequences of periodontal disease, as well as its therapeutic response, is important in evaluating the results of periodontal treatment from the perspective of patients. ${ }^{10}$

VAS has been shown to be simple to administer, reliable and valid, and has been used to evaluate dental pain. Hence Matthews and McCullocht used visual analog scales to investigate differences between patients in their assessment of surgical and non-surgical periodontal treatment.

There are studies in the literature which assess the pain perception after surgical procedures like modified widman flap, gingivectomy, open flap with osseous resection ${ }^{5}$ and implant surgeries. ${ }^{6}$
There are studies which assess the pain perception after nonsurgical procedures like scaling ${ }^{2}$ and root planing. Since no previous study had been carried out comparing pain perception after surgical (open flap debridement raising kirkland flap) and nonsurgical procedure (root planing), this study was conducted to assess the perception of pain after surgical and nonsurgical therapies.

In the study groups there were no statistically significant difference in the age or gender distribution. There were statistically significant difference present between the time duration of the treatment procedure among all the 3 groups. When pain perception level was scored using VAS, there were statistically significant difference present among all the 3 groups, between the healthy and surgical group and between the surgical and non-surgical groups. There were no statistically significant difference present between the healthy and non-surgical group. There was no statistical difference in age, gender distribution, duration of time among the 3 groups.

The results obtained in our study showed no statistically significant differences between male and female patients' discomfort during periodontal treatments which was in accordance with the study conducted by Canakçi CF et al. ${ }^{5}$ 


\section{JMSCR Vol||09||Issue||07||Page 173-183||July}

The results obtained in our study showed there was statistically significant differences existed in terms of duration of the time taken for the surgical procedure which were in accordance with the study conducted by Niklaus P. lang et al. Shorter surgery duration was associated with lower VAS scores. ${ }^{11}$

\section{Conclusion}

The results of our study showed that pain perception level was similar in terms of age and gender distribution, which decreased with shorter duration of time. However surgical procedure (kirkland flap) was found to be more painful compared to scaling and root planing procedures. The results of our study would be beneficial by adopting shorter time duration for the periodontal treatment procedure.

\section{References}

1. Świeboda P, Filip R, Prystupa A, Drozd M. Assessment of pain: types, mechanism and treatment. Pain. 2013;2(7).

2. Sanikop S, Agrawal P, Patil S. Relationship between dental anxiety and pain perception during scaling. Journal of oral science. 2011;53(3):341-8.

3. Canakci CF, Canakci V. Pain experienced by patients undergoing different periodontal therapies. The Journal of the American Dental Association. 2007 Dec 1;138(12):1563-73.

4. Fardal $\varnothing$, Johannessen AC, Linden GJ. Patient perceptions of periodontal therapy completed in a periodontal practice. Journal of periodontology. 2002 Sep 1;73(9):1060-6.

5. Canakci CF, Canakci V. Pain experienced by patients undergoing different periodontal therapies. The Journal of the American Dental Association. 2007 Dec 1;138(12):1563-73

6. Mei CC, Lee FY, Yeh HC. Assessment of pain perception following periodontal and implant surgeries. Journal of clinical periodontology. 2016 Dec 1;43(12):11519.

7. Scott DA, McDonald WM. Assessment, measurement and history. Acute Pain. $5^{\text {th }}$ Edition2008 Sep 26.

8. Locker D. The symptom iceberg in dentistry. Treatment- seeking in relation to oral and facial pain. J Can Dent Assoc 1988; 54:271- 4.

9. Luiz RR, Costa AJ, Nadanovsky P. Questionnaires. In: Epidemiology and Biostatistics in Dentistry. Edition rev and ampl. São Paulo: Atheneu; 2008. p. 273.

10. Locker D. Measuring oral health: A conceptual framework. Community Dent Health 1988; 5:3- 18

11. Tan WC, Krishnaswamy G, Ong MM, Lang NP. Patient- reported outcome measures after routine periodontal and implant surgical procedures. Journal of clinical periodontology. 2014 Jun;41(6):618-24. 


\section{ANNEXURE-1}

ASSESSMENT OF PAIN PERCEPTION AFTER SURGICAL AND NONSURGICAL PERIODONTAL THERAPY

1. NAME OT THE PATIENT:

2. AGE

3. SEX:

4. TREATMENT DONE:

5. DURATION OF THE PROCEDURE:

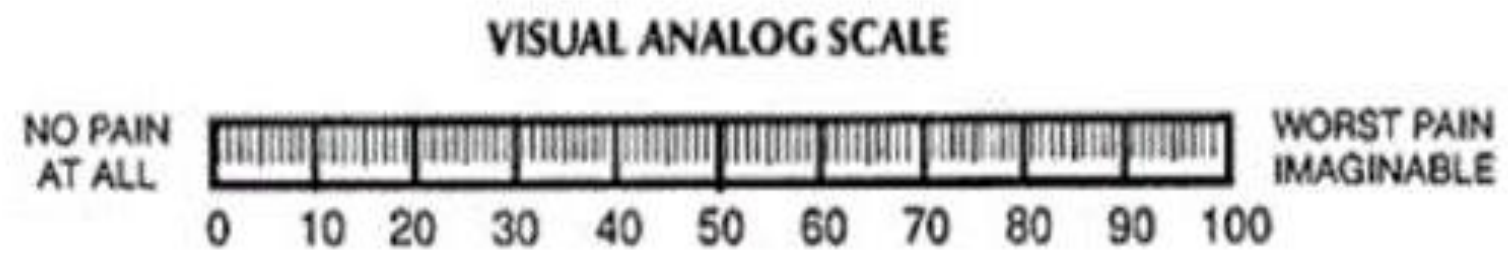

PAIN SCORES:

O-4: NO PAIN

5-44: MILD PAIN

45-74: MODERATE PAIN

75-100: SEVERE PAIN 